\title{
Complexity of manufacturing systems- subject oriented knowledge processing and control
}

\section{J. Peklenik}

Department of Control and Manufacturing Systems, University of Ljubljana, Slovenia, Aškerčeva 6, 1000 Ljubljana Telephone: (386) 611771 215, Fax: (386) 61218567 E-mail: janez.peklenik@fs.uni-lj.si

\begin{abstract}
It can be assumed that the future developments in manufacturing technology and systems will be influenced by globalisation of the markets, diversification and innovation of products, developments of new materials, ever increasing environmental considerations; and assisted by the sophisticated ways and means of the manufacturing and information technologies. In order to meet the challenges we have to search for a new paradigm in manufacturing which may provide new approaches of how to structure, operate and control the manufacturing systems in the future. In this paper first a framework for manufacturing development and manufacture of products will be given, then a cybernetic and an information model of a work system will be discussed giving data on the complexity of information and control in manufacturing systems. Finally subject oriented knowledge processing and control will be discussed in details.
\end{abstract}

\section{Keywords}

Complexity, knowledge processing, work system models, competence 


\section{MOTIVATION AND PROBLEM DEFINITION}

The diversity of products resulting in general from the advancements in R \& D, inventions and improvements in the design, etc., lead predominantly to small lots and increased complexity in the fabrication of these products.

The consequence is that a manufacturing company must respond to the market impacts in the shortest time possible. To be the first on the market means a great advantage in terms of competition, market share and time in which the predominate role of the company is uncontested.

In order to respond to these impacts, a manufacturing company must exhibit the following features:

- a flexible and adaptable organisational structure;

- the decision making processes on all levels must be based on well designed and implemented information system supporting competent Subjects (we use the term "SUBJECT" for human operator, designer, programmer, group or team leader, team, group manager, department head, managing team, policy making body etc), involved in the decision making processes;

- the self-organisation of the work processes, necessary for creating, manufacturing and marketing of innovative products is an unavoidable element of the manufacturing dynamics, which the Subjects must be able to master on all levels of activities;

- a company must be able to create continuous improvements on products and manufacturing technologies following the law of evolution.

The response time is, in every aspect of manufacturing activities, decisive and depends greatly on the factors listed above. However, in centre of these activities affecting the dynamics of manufacturing is the Subject with his knowledge and competence.

The Subject has to make various decisions instantly and on every level as required: from the job level to the managerial level.

At present, but even more in the future, the human-machine systems shall require Subjects, able and competent to adapt constantly to unforeseen situations and demands, occurring within the terms of reference.

The decision making process implemented by the Subject is based on the information available and the knowledge which the Subject processes and is capable of using it in a concrete situation and in a rational way.

Of course, the information and the knowledge about the participating systems and subsystems are affected by the internal as well as the external stochastic dynamics of the market (the machinery and the synergetic effects of a complex object of control - the factory) resulting in incomplete and uncertain information, and consequently, very often in inaccurate knowledge. 
The focal point in the Subject orientated knowledge processing and control is the ability and competence of the Subject to select, synthesise and apply relevant information for structuring, operating and control e.g. of a factory system (FS) or an unit element of the manufacturing environment. In order to establish the role of the Subject on various levels of manufacturing activities it is convenient to determine the terms of reference of the object in the discussion. Therefore, the object - the factory system for manufacturing discrete products will be presented in very basic organisational form as a complex multilevel adaptive manufacturing system.

\section{A FRAMEWORK FOR MANUFACTURING DEVELOPMENT AND MANUFACTURE OF PRODUCTS}

The desire of people to make a product steams basically from the motivation, which can be of different origin. The people:

- want to make money;

- $\quad$ are eager to explore new ideas;

- want to improve the quality of life;

- want to strengthen the defence capabilities; etc.

In order to realise the motives and wishes, it is necessary to have some new ideas or innovations, sufficient knowledge as well the ways and means to accomplish the objectives. Let us first develop a model of a work system (WS) based on some general ideas of interfacing man, machines, technologies, knowledge and information. Figure 1 yields a very basic model of a work system with major entities required for the production implementation.

Let us examine the entities relevant in this respect.

The object represents the manufacturing system with a set of inputs $\{X\}$ and a set of outputs $\{Y\}$ as products defined as a set of the desired objectives $\left\{Z^{*}\right\}$ specified by the Subject.

The Subject controls the object through a set of control actions $\{U\}$, simultaneously assessing the inputs $\{\mathrm{X}\}$ and the outputs $\{\mathrm{Y}\}$ by measuring or/and estimating the input information $I_{x}$ and the output information $I_{y}$. The decision making of the Subject about the set of inputs $\{X\}$ and the checking of the set of objectives $\left\{Z^{*}\right\}$ require activities of the Subject, giving him the predominant role in controlling the object. 


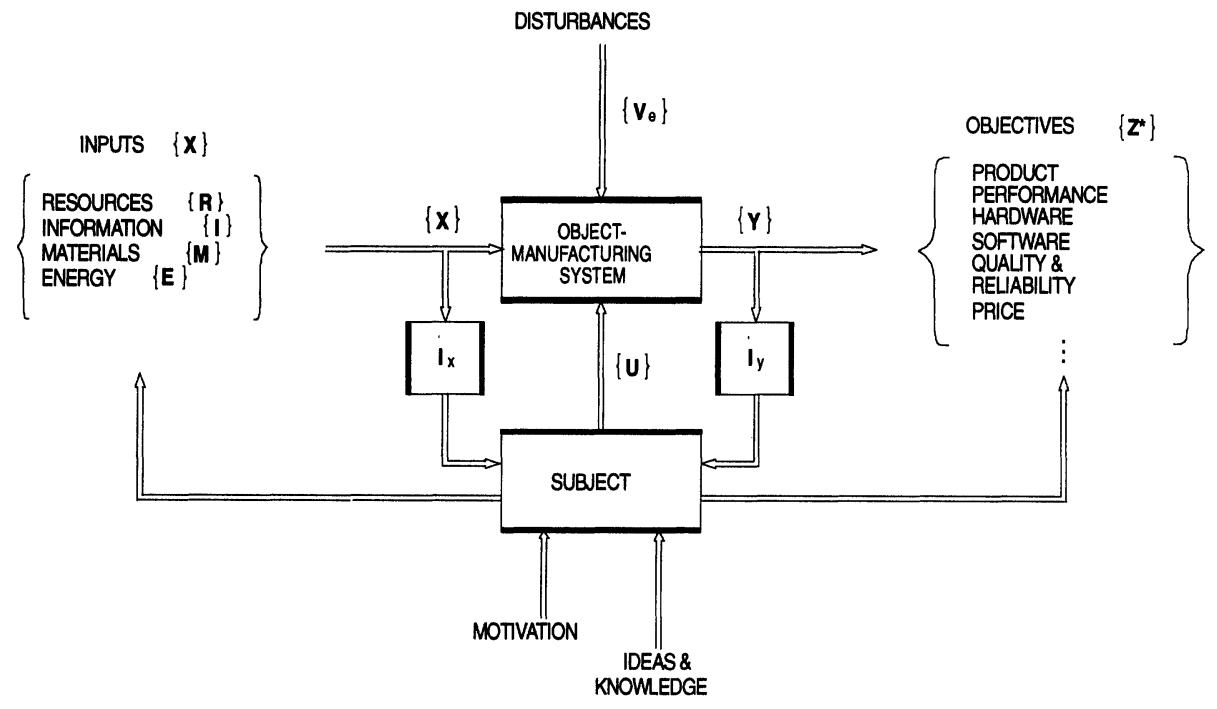

Figure 1: Basic elements of a work structure.

The inputs $\{\mathrm{X}\}$ include the following major entities required for the development and manufacturing discrete products: resources $\{R\}$, information $\{I\}$, materials $\{M\}$ and energy $\{E\}$.

The resources $\{R\}=r_{1}, r_{2} \ldots R_{R}$ incorporate finance, personnel, management, buildings, machinery, computing equipment, various technologies, etc.;

The information $\{I\}=i_{1}, i_{2} \ldots i_{i}$ : contains various types of information relevant for marketing, engineering, management, and manufacturing.

The materials $\{M\}=m_{1}, m_{2} \ldots m_{m}$ : for the manufacturing of a product we need various materials, standard parts, units and subsystems bought from external producers, auxiliary materials, etc.

The energy $\{E\}=e_{1}, e_{2} \ldots E_{E}$ : for implementation of necessary production functions such as driving of machines, transportation equipment, communications, information processing etc., we need energy of different kind and intensity.

The output of a manufacturing system is a product, specified by a set of output parameters $\{Y\}$. However, the subject defines the objectives $\left\{Z^{*}\right\}$, which are expressed in the language and by the definition of the Subject. That is to say that the objective $\left\{\mathrm{Z}^{*}\right\}$ is expressed by the state of the output $\{\mathrm{Y}\}$ and a translation coefficient $\Psi$. Hence,

$Z^{*}=\Psi(Y)$

Desired objectives $\left\{Z^{*}\right\}$, set by the Subject, are: the product performance, its quality and reliability, competitive price and time to delivery. These are the major 
factors affecting the market success of a product. Let us give a brief account of the individual objectives.

The performance characteristics are the major criteria for assessing the competitive edge of a product. They depend strongly upon the ability of engineers and scientists to transform innovative ideas and discoveries into new and better products in a short time and in proper timing.

In direct correlation with the performance and the market success of a product is the quality of its development and the level of efficiency related to the manufacturing capabilities to transform an innovation into a marketable product.

The second major factor affecting the position of a product is its quality, related to the life expectancy, reliability of functioning and serviceability. A decisive influence on this set of factors is provided by the policy of the decision markers, defining the level of the product quality and reliability and determining the means for its realisation.

The competitive price, as one of the most important objectives specified by the Subject, is in strong correlation with the ability of the management to structure, integrate and control the manufacturing systems and technologies in order to accomplish the optimal production costs.

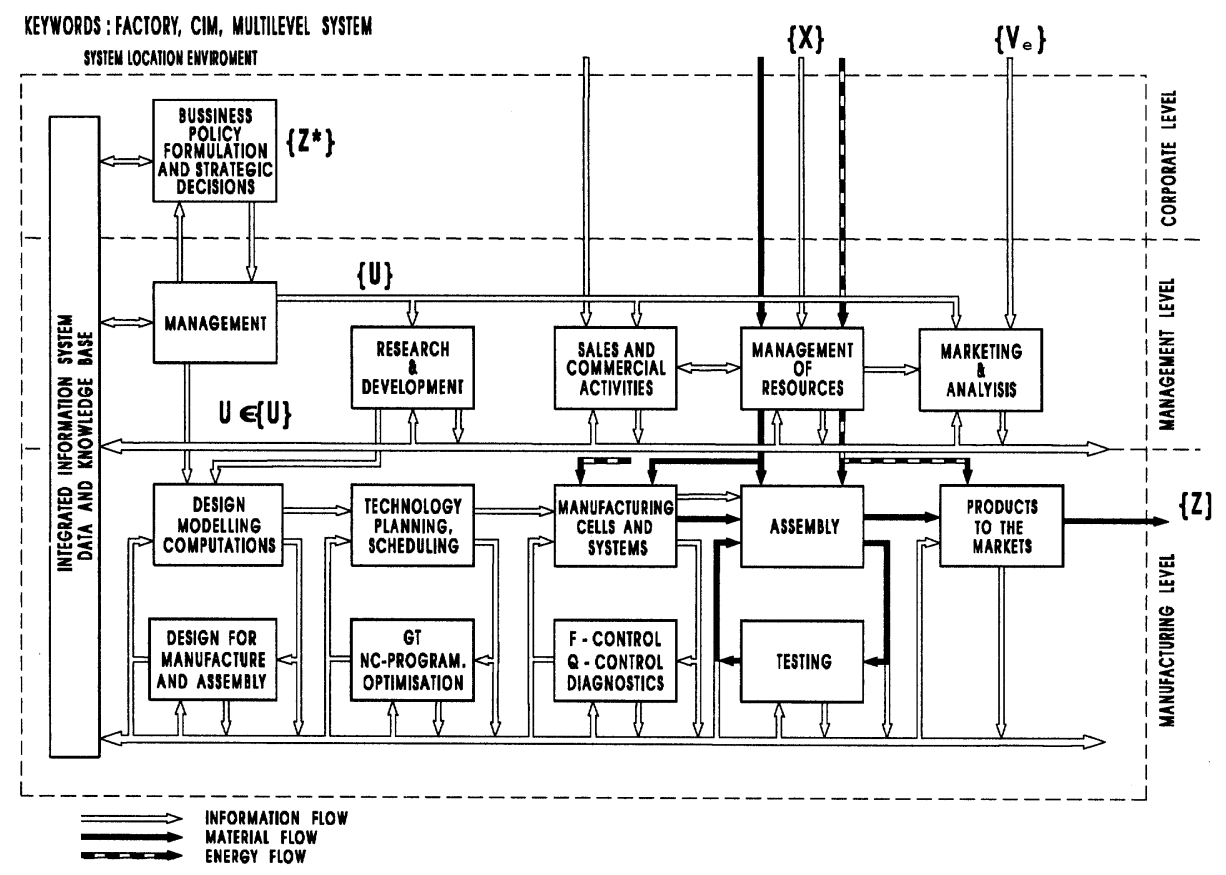

Figure 2: Factory as a large complex multilevel adaptive system. 
A factory is structured in three levels - the corporate (level 1), the managerial (level 2) and the manufacturing (level 3).

The corporate level sets the terms of references for the business policy. This set of desired objectives $\left\{Z^{*}\right\}$ is related to the type of products, the volume and product mix, management, financing, location, profit, etc..

The managerial level incorporates the factory management, responsible for implementing the policy set up by the board on the corporate level. In addition to the organisational, planning, supervisory and control functions, it is responsible also for research and development of products and technologies, marketing research, sales and commercial activities as well as the management of resources, required for a cost-efficient manufacturing of products set within the terms of references.

The manufacturing level consists of a number of subsystems necessary for transforming an innovation or a prototype into a marketable product.

Design, modelling and computation functions generate detailed technical information about the product as a whole and also detailed information on components, including materials, shapes, dimensions and their relations, tolerances, surface integrity, etc.

An important activity in this context is the design for manufacture and assembly. This can be stipulated when the basic configuration of a product in its structure, detailed composition and interrelations of its components, are known. The knowledge and rules applied to accomplish a better manufactureability and assembleability represent an important part of the design process, decisively affecting the productivity of manufacturing and assembly systems. This activity is allocated, for reasons already revealed, in the feedback loop of the design subsystem.

The design information is conveyed to the technology planning and scheduling subsystem. The process and operation planing result in information on how the individual components must be fabricated, which includes a detailed description and sequence of processes and operations, as well as the optimal process conditions. It also determines which machines will be used for the fabrication of parts, tool selection, the measuring means, etc. The composition of part families as an important step, related to the technological common denominator, is selected as a result of CAPP analysis. The NC-programming and the optimisation of the fabrication processes represent also the activities within this subsystem.

The second major function of this subsystem is the planning of the logistics of the material flow resulting from scheduling of parts with regard to the machines, their capacity, timing, etc.

The CAM-subsystem consists of a number of FMC and FMS which are structured according the GT-principles and integrated via LAN and transportation logistics into an integrated FMS. The feedback loop incorporates the F-control (Fabrication), the Q-control (Quality) as well as the diagnostics, intended to ensure the availability of the equipment. 
Both previous subsystems deal basically with the generation of technical and technological information. The CAM subsystem, however, is intended to fabricate parts of the products.

In this point, it is necessary to add to the information flow also the material and energy flow.

The assembly subsystem executes the assembly of products and their testing. In addition to the information required for this process, the flow of the parts fabricated in the CAM-subsystem and the parts obtained from outside, as well as the standard parts, is required.

An important integrative role is intended for the communications between the building blocks of the factory system interconnecting the data and knowledge base (DKB) with every unit and activity in the system. Figure 3 reveals an integrated DKB for the manufacturing level-design, planning fabrication, assembly and dispatch. Every level in the factory has a correspondingly structured DKB.

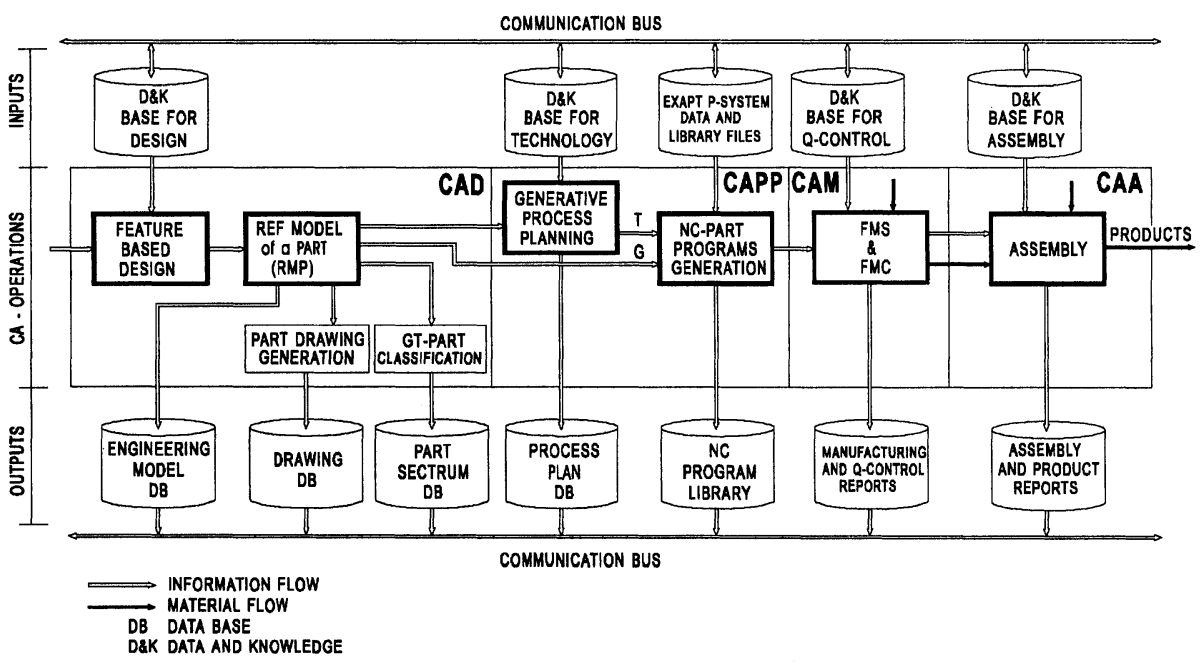

Figure 3: Structure of a data base for manufacturing level.

The factory system, as described in this chapter, is located in an industrial environment. The dynamic of the market, influences decisively the behaviour of FS and the decision-making processes. 


\section{STRUCTURE OF A MANUFACTURING WORK SYSTEM}

A factory system, structured as shown in Figure 2, reveals a number of interfaced subsystems with specific functions and objectives. It can only be implemented by usually interconnected elementary manufacturing work system (WS) of various types. Each of these WS is intended to implement a work process such as product development and design, process planning, fabrication of parts, quality control, assembly, managing \& decision making, supervision, etc.

In order to conduct a fruitful discussion on present and future concepts on the role of knowledge and information processing in structuring, operating and controlling it might be useful to develop a generic model of a work system. Basically a WS consists of a process, the process implementation device (PID), and the Subject. These three major elements are interconnected in order to accomplish the objectives. The Subject influences decisively the entire work process by setting the desired objectives $Z^{*}$, which the Subject (S) seeks to accomplish (Peklenik, 1988, 1992), by controlling either the PID or/and the process, using his knowledge and experience.

Two types of models for the analysis of WS have been proposed (Peklenik, 1992, 1997):

- the cybernetic model and

- the information model.

The cybernetic model is used to study the structure and the dynamics of the WS and is using for analysis and synthesis the control systems theory.

The operation and control of WS require however the decision making based on available information. Therefore, an information model of the WS provides the framework for these studies.

\subsection{The cybernetic model of the work system}

Figure 4 exhibits the basic cybernetic architecture of a WS. From the environment, a set of inputs $\{X\}=\left\{X_{1}, X_{2} \ldots X_{n}\right\}$ enters the process $G_{p}$ with the objective to transform them into a set of output parameters $\{Y\}=\left\{Y_{1}, Y_{2}, \ldots, Y_{n}\right\}$ which correspond with the set of desired objectives $\left\{Z^{*}\right\}$. The relation between the output parameters and the objectives is given in Eq. (1).

A work process (e.g. machining, welding, computing etc.) can only take place if a Process Implementation Device (PID) (e.g. machine tool, computer, measuring instruments, painting or welding equipment etc.) is providing the necessary conditions for it. The Subject $G_{s}$ is supervising the input information $I_{x}$ and the output information $I_{y}$ and comparing it with the set of references $\{R\}$. The decision making of the Subject results from the comparison between $R$, and $I_{y}$ if $R-1_{y}$ ? 0 .

Therefore it is significant that the Subject (or the controller, if it exists) constantly assesses the output information $I_{y}$ and compares it with the given 
references $\mathrm{R}$. He can decide whether any control action by the control signals $\{\mathrm{U}\}$ is required in order to adapt the PID accordingly or/and to optimise the conditions under which the process is executed.

\subsection{The information model of a work system}

The information in a work system is essential for an effective operation and control of WS. The dynamic response of a WS to unpredictable excitations and distortions depends significantly on the quality and reliability of information, as well as the ability of the Subject to synthesise and to use it for its control.

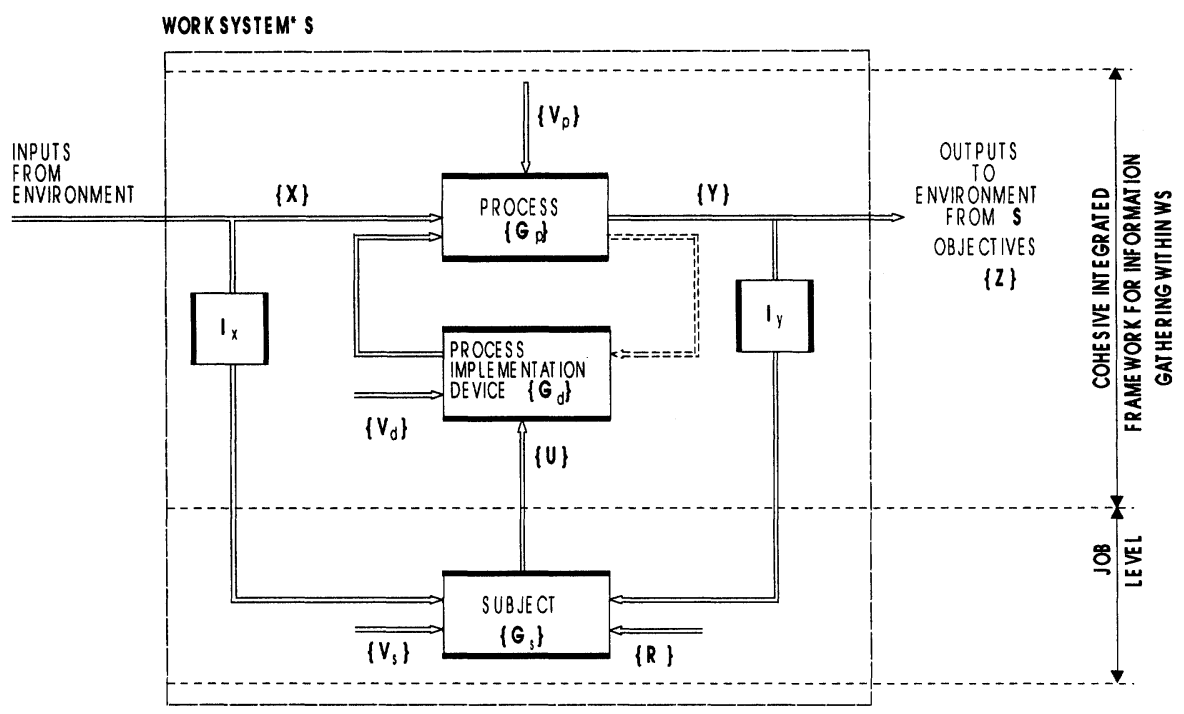

Figure 4: Cybernetic model of the elementary work system.

If the cybernetic model of WS is treating basically the dynamics of the system, is on the other hand the information model dealing with information transmission, as measure of relatedness between variables, which are not in every case statistically independent. However it should be stated that between the system dynamics and the information, governing the operations, there is an important relation, which must be taken into the considerations.

Figure 5 exhibits an information model of a Work System WS, or System S for short (Peklenik, 1997). For reason of convenience the system S, selected for an explanation, represents a basic machining system with a manual control. It consists e.g. of four subsystems: the process, the process implementation device PID, the 
Subject and the measuring device. The variables of the system $S$ needed for the operation are according Conant (Conant, 1976) of two types: from the environment directly observable variables of the system S, constituting a set of output variables.

$S_{o}=\left\{M_{p}\right\},\left\{G_{p}\right\},\left\{S_{p}\right\}$

INPUTS FROM
ENVIRONMENT
OF S

OUTPUTS TO

ENVIRONMENT

OF S

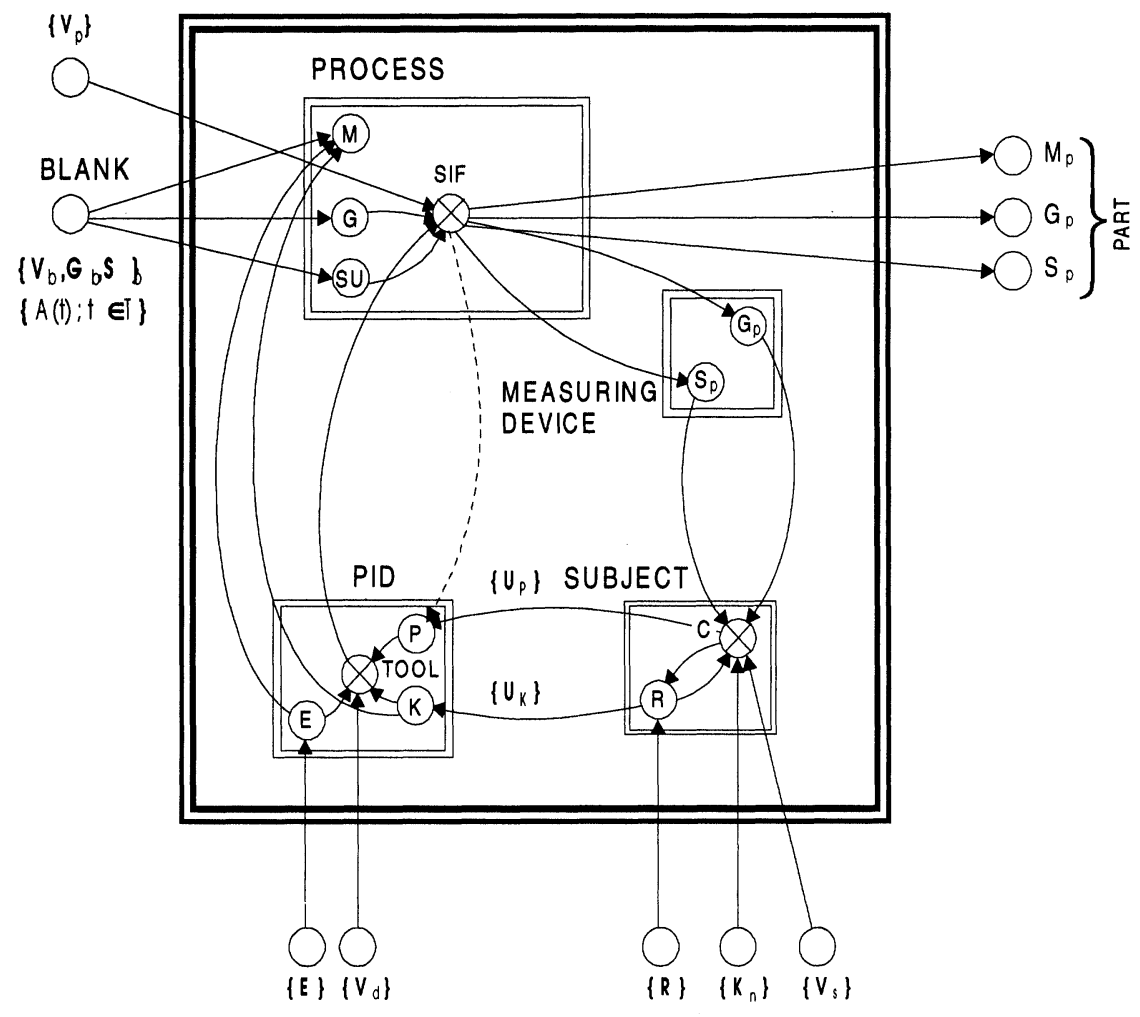

INPUTS FROM ENVIRONMENT TO $S$

Figure 5: Information model of a work system S with its SIF subsystems.

The remaining variables are internal variables constituting the internal system 
$\mathrm{S}_{\mathrm{int}}=\left\{\mathrm{M}_{\mathrm{b}}\right\},\left\{\mathrm{G}_{\mathrm{b}}\right\},\left\{\mathrm{S}_{\mathrm{b}}\right\},\{\mathrm{E}\},\{\mathrm{P}\},\{\mathrm{K}\},\left\{\mathrm{U}_{\mathrm{p}}\right\},\left\{\mathrm{U}_{\mathrm{k}}\right\}$

Process, PID, Subject, M-Device

For the system $\mathrm{S}$ holds

$\mathrm{S}=\mathrm{S}_{\mathrm{o}}, \mathrm{S}_{\mathrm{int}}$

The internal variables of the $S_{\mathrm{int}}$ are briefly discussed in order to illustrate the concept.

The blank is a piece of material described with sets of mechanical $\left\{M_{b}\right\}$, geometrical $\left\{\mathrm{G}_{\mathrm{b}}\right\}$ and surface $\left\{\mathrm{S}_{\mathrm{b}}\right\}$ properties. The probability distributions of these properties are known, or if not, they must be determined experimentally. The time dependent properties of the blank constitute stochastic processes which are of importance for identifying the dynamics of the machining.

The process is a subsystem $S_{0}$ of the system $S$ which constitutes the sets of output variables $\left\{\mathrm{M}_{\mathrm{p}}\right\},\left\{\mathrm{G}_{\mathrm{p}}\right\},\left\{\mathrm{S}_{\mathrm{p}}\right\}$ observed directly. The Eq.(2) expresses an assumed composition of the subsystem $S_{0}$ from the environment. The generation of a part with a required shape, dimensions and surface quality take place in the surface interface SIF, [Peklenik 1986].

The PID, in this case the machine tool, provides the internal variables for the process implementation such as the energy $\{\mathrm{E}\}$, the positions $\{\mathrm{P}\}$ between the tool and work-piece, the speeds $\{\mathrm{K}\}$ for driving the tool $\left\{\mathrm{K}_{\mathrm{l}}\right\}$ and the blank $\left\{\mathrm{K}_{b}\right\}$. The internal variables $\{P\}$ and $\{K\}$ are predetermined and specified in the reference $\{R\}$ (drawing and process planning sheet).

The Subject is setting, according the reference $\{R\}$, the process conditions $\{P\}$ and $\{\mathrm{K}\}$ on the PID. It also observes, by means of a measuring device, the generated geometrical and surface variables $\left\{\mathrm{G}_{\mathrm{p}}\right\}$ and $\left\{\mathrm{S}_{\mathrm{p}}\right\}$ of the part, which are considered as output variables. The information on generated geometry and surface quality given by the reference $\{R\},\left\{G_{R}\right\}$ and $\left\{S_{R}\right\}$ is compared by the Subject with the corresponding output variables. In case of differences the Subject initiates the control action by $\left\{\mathrm{U}_{\mathrm{p}}\right\}$ or/and $\left\{\mathrm{U}_{\mathrm{k}}\right\}$.

Hence, the Subject is governing with the internal variables the PID directly and the process indirectly. Therefore the Subject belongs to the internal system $S_{\text {int }}$ of the system $\mathrm{S}$ as expressed in Eq.(3).

The role of the Subject is therefore :

1. to select the process conditions in relation to the material properties of the blank $\left\{M_{b}\right\}$, the geometrical accuracy $\left\{G_{p}\right\}$, and the surface quality $\left\{S_{p}\right\}$ of the part;

2. to compare the set of references $\{R\}$ with the actually generated geometrical accuracy $\left\{G_{p}\right\}$ and surface quality $\left\{S_{p}\right\}$ and if necessary to control the Ppositioning and K-kinematics subsystem by a set of control signals $\left\{\mathrm{U}_{\mathrm{P}}\right\}$ and $\left\{\mathrm{U}_{\mathrm{k}}\right\}$. 


\section{COMPLEXITY OF INFORMATION AND CONTROL IN MANUFACTURING WORK SYSTEMS}

In the above discussion an attempt has been made to identify the basic structure of a factory and to describe a typical work system as a deterministic entity for manufacturing. We argued that the Taylor principles, developed during the first industrial revolution, dictated mainly the formation of work structures and operations, based on deterministic and predictable information and control. However, observing these structures and processes more closely, we will find that the identification of the dynamic behaviour, as well as their control and optimisation are problems of immense proportion, due to the complexity of the objects. The influences resulting from the environment, Figure 2, such as market requirements, the general economic situation, competition, etc., are considered as a set of external disturbances of stochastic nature $\left\{\mathrm{V}_{\mathrm{e}}\right\}$, affecting the control and optimisation of the factory operation. The time response of the system to these random disturbances depends very much upon the ability of the management to take proper measures, and make the right decisions on time. This activity is, however, based more or less on guessing, due to the fact that the dynamics of the factory, and the character of the external disturbances $\left\{\mathrm{V}_{\mathrm{e}}\right\}$, are not sufficiently clarified. The implementation of the decisions will depend very much on the adaptability of the factory as a whole and on the flexibility of the elementary work systems in particular. The adaptability of a factory to the external disturbances depends upon the time response of the individual work systems and their coordination, in which the Subject, as an important part of the system, plays a decisive role. This Subject, however, operates with incomplete information and with insufficient knowledge.

Hence, the problems to be addressed in manufacturing in the future must be directed towards the complex phenomena of fluctuations, the non-linear nonequilibrium systems, and the self-organisation of the work systems, as well as the evaluation problems.

Several illustrative examples will be given in order to argue the case that the manufacturing systems must be treated as complex objects of control.

\subsection{Character of the information in a work system}

The information in a work system $S$ exhibits various types and characters. The variables constituting the internal subsystem $S_{\text {int }}$ and the output subsystem $S_{o}$ are of discrete or/and continuous nature. The discrete variables are either deterministic or random. The time dependent variables with a deterministic character are described by various functions. However, the predominant character of the time dependant random variables is described as stochastic processes. In case that a set of 
observations is arranged chronologically, e.g. the incoming orders of $\mathrm{N}$-quantities of a product $\mathrm{A}$, over a period of time $\{\mathrm{X}(\mathrm{t}), \mathrm{t} \in \mathrm{T}\}$ is called a time series, Figure 6 .

The independent random variables are described by the probability density, which can in majority of cases only be determined by the experiments. The same applies for stochastic processes and the time series. For instance, the time dependent mechanical properties of a blank with random variables in the material, entering a machining process, constitute a stochastic process of the input energy which is of significance in determining the process dynamics (Peklenik, Mosedale, 1968).

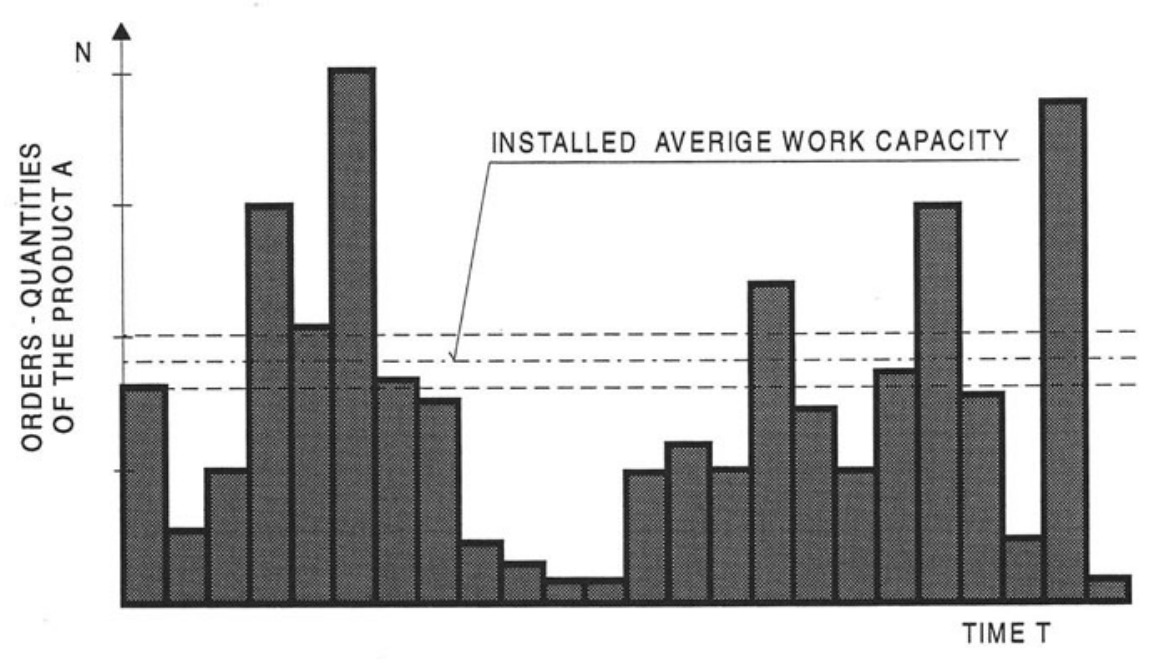

TIME INTERVALS

Figure 6: Time series of incoming orders of the product A.

Between the system variables there are dependencies affecting the system's operations and control. The external disturbances are shown in Figure 4 as sets of $\left\{\mathrm{V}_{\mathrm{p}}\right\},\left\{\mathrm{V}_{\mathrm{d}}\right\}$ and $\left\{\mathrm{V}_{\mathrm{s}}\right\}$ influencing the process, PID and the Subject. There are of random nature. The inherent random disturbances are parts of the system variables. Their influence is reflected in the probability densities, the correlation functions, and the power spectra of positions; speeds, forces, vibrations, energies, geometrical and surface roughness variables, to name only a few.

The above statements are valid for the independent variables. However, between the subsystems also the mutual relations do exist. They are expressed by the conditional probability density distributions indicating the non-independence between two or more random variables of the subsystems. For a comprehensive 
analysis of the information flow in the system, the knowledge describing quantitatively these interrelations, is required.

The information for operations and control of work systems available in various forms, such as data, knowledge, experience, expertise, is not only uncertain, but it is also incomplete. Therefore the Subject has to operate the system under unpredictable conditions and incomplete information. This state of affair requires, however, decision-making procedures based on competence of the Subject to make it up for lack of relevant and reliable information.

\subsection{Some observations of the complexity in manufacturing}

In this discussion we shall analyse two examples in order to obtain some general ideas on how to assess the a complex its in manufacturing.

\subsubsection{Manufacturing processes}

Let us examine the mechanism of the grinding process, as shown in Figure 7. Grinding represents a typical material removal process with a perfectly randomly structured tool - the grinding wheel (Peklenik, 1957, 1961). The cutting elements the grains, their dimensions and the spatial distribution of grains, the orientations and the strength of the bond bridges, the properties of the cutting edges and their geometry etc., can only be described by the statistical analysis.

The mechanism of the surface generation in grinding in shown in Figure $7 a, b$. The cutting profile $X^{B}(1)$ at the input interfaces with the surface profile $X^{A}(1)$ of the blank over a contact length $l_{e}$, and the entire width of grinding L. On the other hand, the structure of the material to be ground consists of different components (grains, bond) exhibiting variable geometrical and physical characteristics with stochastic character.

During material removal in some areas both stochastic profiles overlap. The result is the generation of a number of chips with various cross-section areas $A_{c}$. The estimation of $A_{c}$ yields a statistical distribution $f\left(A_{c}\right)$, as shown in Figure $6 c$ (Peklenik, 1964, 1974). The first approximation of the distribution $f\left(A_{c}\right)$ indicates a strong positive skewness towards large $\mathrm{A}_{\mathrm{c}}$-values. This causes larger cutting forces on the individual grains, hence the result is discriminate breakage of grains out of the grinding tool structure.

The problem which we have to address in order to find a solution is how to identify the grinding process by an operator $\mathrm{G}^{0}$ representing the relation between the output $\mathrm{Y}^{\mathrm{A}}$ and the inputs $\mathrm{X}^{\mathrm{A}}, \mathrm{X}^{\mathrm{B}}$ considering a set of external disturbances $\left\{\mathrm{V}_{\mathrm{p}}\right\}$ affecting the process.

We would find a similar situation while identifying other manufacturing processes. The deterministic process modelling cannot be used in developing of a new solutions based on comprehensive identification.

Therefore the manufacturing processes are exhibiting very high complexity as shown in grinding example. The classical methods of process identification do not 
consider the complexity of the process and cannot be used effectively for an adaptive control of manufacturing processes.
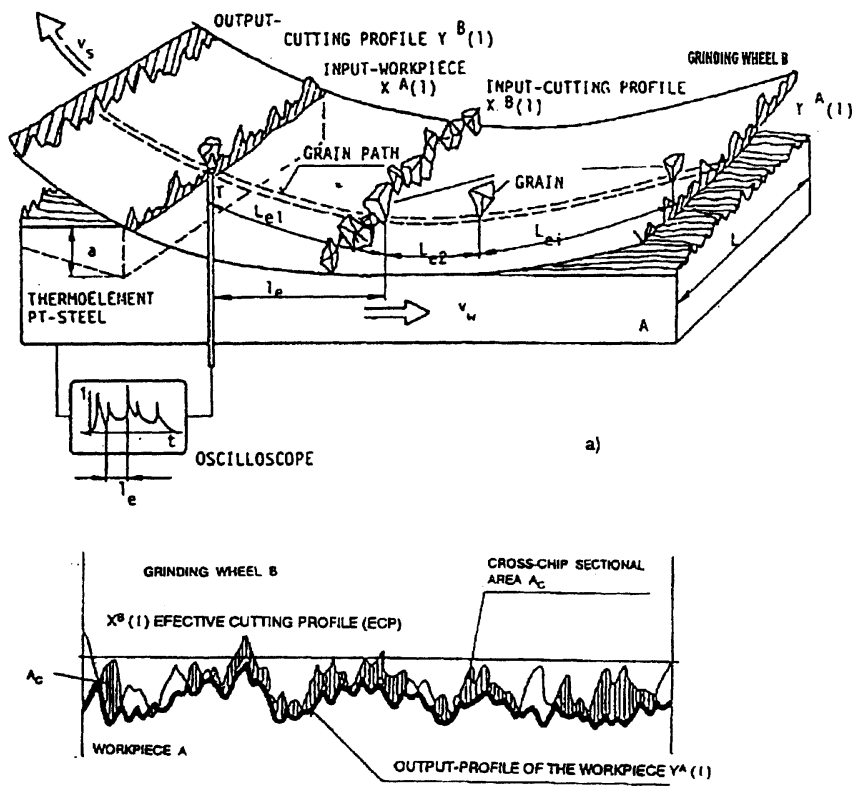

b)

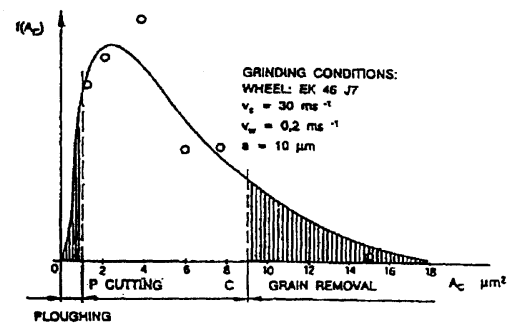

Figure 7: Generation of a surface in grinding: a) mechanism of grinding b) forming chip cross sectional areas $A_{c}$, c) distribution density $f\left(A_{c}\right)$.

\subsubsection{Performance, availability and efficiency of FMS}

A flexible manufacturing system (FMS) represents a complex object of control and should be examined regarding its performance, availability and efficiency of the operations. As an example we will try to show how a simple FMS-system, consisting of two CNC-machining centres, a 3D-measuring machine and a washing machine, operates under real conditions, trying to accomplish the objectives $\left\{Z^{*}\right\}$, 
set by the Subject as Figure 8 indicates. The structure of the FMS can be further decomposed in terms of individual system units, as shown in Figure 4 and 5.

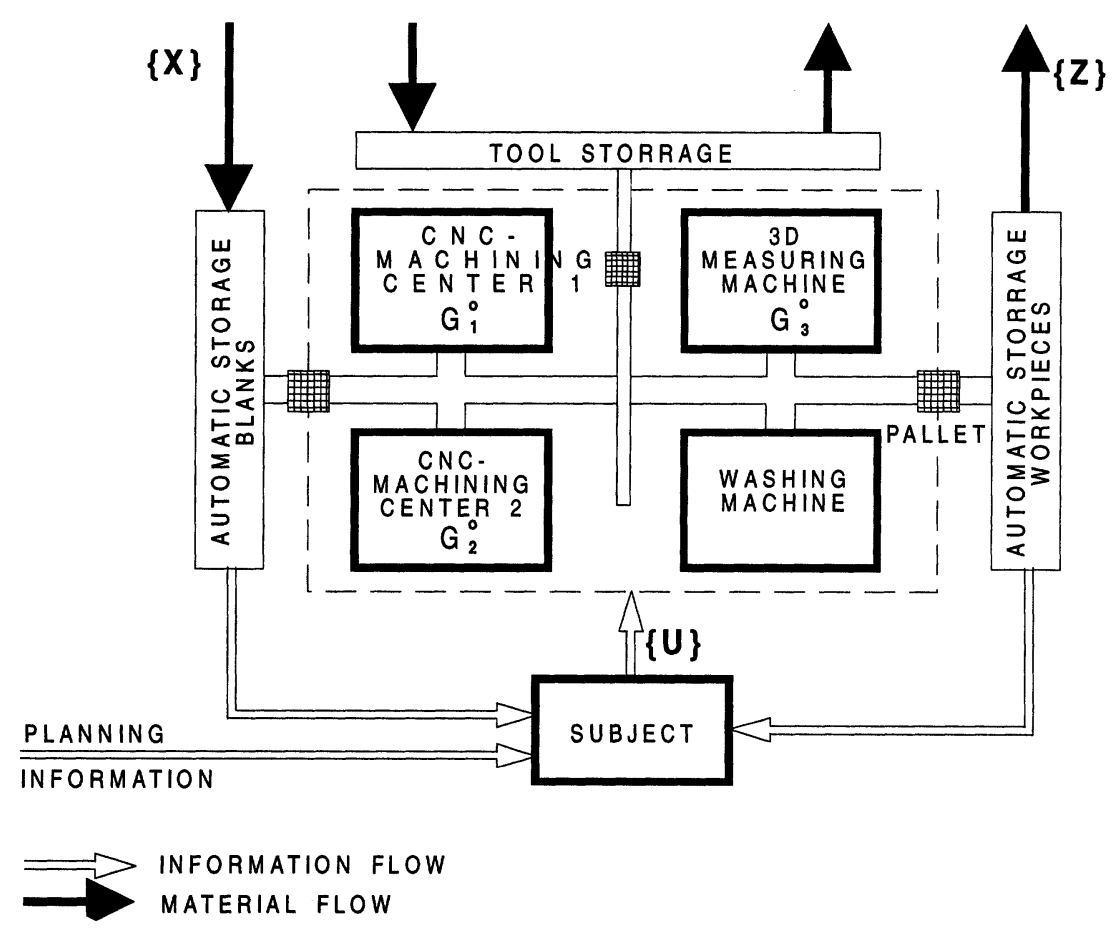

Figure 8: Structure of a FMS supervised by a Subject.

The performance of a FMS is determined by

- the material removal rate over the operation time in which a new value is generated;

- the quality of the parts must be maintained constant during the fabrication, (dimensional and shape tolerances, surface integrity), and should not deteriorate.

It depends upon the time dependent geometrical and physical parameters of the machine tool performing the machining, tooling, the ability of the control system (CNC) to follow the reference instructions with an accuracy required, and to adapt the machine tool when the disturbances (tool wear, thermal deformation, vibrations, etc.) affect the performance of the machining system. 
The availability of the machining system basically a function of the mean time between failures (MTBF) of the equipment, control and measuring system and particularly the tools. The tool breakage, the sensor failures, etc. affect the MTBF and can be specified as unpredictable events.

The efficiency (EF) of the FMS is defined as a ratio

$$
\mathrm{EF}=\frac{\text { time in which a FMS generates a new value }}{\text { total time available to generate a new value }} \times 100 \%
$$

and is a function of many factors, such as the degree of automation and flexibility of the equipment, the input configuration regarding part grouping and scheduling, the requirements for the implementation of just-in-time principles, tooling, NCprogrammes, tool and fixtures, pallet changes, logistics, etc. The higher availability of FMS greatly increases its efficiency. It was reported that the FE-values achieved in the industrial environment could amount up to $75 \%-80 \%$, (Hirai et al, 1988).

As we can see, there are many possible external and internal disturbances of statistical and stochastic nature, many non-linear behaviours of the FMScomponents, generating non-equilibrium states of the system, some of which exhibit fully unpredictable properties. Furthermore, the decisions and the supervisory control of the FMS are executed by the Subject, with limited ability and knowledge to cope with the emerging problems and incomplete data during the operation of FMS.

\section{CHARACTERISTICS OF THE COMPLEXITY IN MANUFACTURING}

In order to argue the case that the objects to be controlled in manufacturing, the processes, machine structures, man-machine interfaces etc. exhibit complex behaviour, two examples have been analysed: one on the micro-level (grinding process) and one on the macro-level (FMS). Let us try to find some common characteristics, which can be used to help us in developing better and more efficient information and knowledge tools for operation and control of manufacturing systems.

The first observation made was that a formal mathematical description of the object is not available or/and possible. The operator $\left\{G_{p}\right\}$ of a manufacturing process as shown in Figure 4 is not known and cannot be expressed by the usual mathematical tools. The same is true for the machine tool structures, if one considers that the spring constants and the damping of parallel and/or serial interconnected machine parts can only be roughly estimated. The formal description of the machine tool dynamics by means of a transfer function $G_{d}$ is possible and the machine tool is controllable as long as we do not take into account 
the time dependent temperature changes and dynamic forces of stochastic nature. These influences are generated during the machining process and affect decisively the accuracy of the parts and stability of the system.

In the classical approach, a machine tool has been considered as a simple object of control, following the laws of classical dynamics. However, if we treat the machine tool as a real object with deficiencies in the surface contact areas, unpredictable variations of stiffness and damping, dimensional and shape errors of the machine tool elements, random excitations of the MT-structure etc. than the machine tool represents a complex object of control.

The second general observation which can be made are the stochastic behaviours of the objects. This is an essential characteristic of the complex its, affecting the behaviours of the object due to various internal as well as external sources of random nature. The grinding tool wear, for example, is a very complex process which includes random breakage of grains, softening of the grain tips and the formation of grain flatness, (Peklenik, 1957). The wear process is to be considered as an internal secondary source of disturbances, adding to the generation of stochastic behaviour of this tool.

However, such secondary effects can suddenly trigger major perturbations that may lead to catastrophic events (burning, significant increase of the rate of the tool wear, tool breakage, etc.).

Further characteristics observed in the complex objects of control are their distinct non-stationary behaviour. The evolution of objects as a function of time exhibits in general certain trends of their characteristics. For instance, the increase in the diameter of a ground cylinder, as function of time, results from simultaneously acting tool wear, thermal and elastic deflections and perhaps the errors of the guide-ways, affecting the relative position between the tool and workpiece. The summarising effect produces a non-stationary behaviour of the dimensional and shape parameters of a ground cylinder.

Examining the controllability of a complex object in relation to the Subject, one may find out that the behaviour of the object usually does not in any way conform with the wishes of the Subject to accomplish a desired objective $\left\{Z^{*}\right\}$. That is to say that the object executes his own functions regardless of the intentions of the Subject. Hence, the reluctance of the object to be controlled is also one of the important features characterising its complexity.

The perturbations and non-linearities of the object are responsible for significant variations related to the state of the object $\{\mathrm{Y}\}$, operating under the same conditions. The information on $\{Y\}$ collected at different of times, may significantly deviate from previous measurements.

Summarising these points we may conclude that a complex object in manufacturing can be characterised by several characteristics, as shown in this discussion. The most common and important among them are:

- absence of a formal mathematical description of the object;

- distinct stochastic properties of the object; 
- non-stationary behaviour during the operation;

- reluctance of the object to be controlled and

- irreproducibility of measurements due to significant deviations of measuring data under the same operating conditions.

\section{OPERATION AND CONTROL OF A WORK SYSTEM}

A work system in operation has to adapt itself to the production requirements with a speed appropriate for the market response. This speed depends upon the response time with which the decisions, the control and their implementation must be accomplished. The Subject, bases his decisions on quality and quantity of information available and the capacity of communication channels between the subsystems. Due to large amount of data and their interrelations, some relevant and meaningful information measures should be introduced.

\subsection{Estimates of information measures}

The quantitative estimates of information measures have been developed in the $\mathrm{N}$ dimensional information theory called also the multivariate uncertainty analysis (McGill, 1954, Conant, 1975) and are widely used today in the system analysis. The input into a work system $S$ from the environment constitutes sets of variables forming the internal subsystem $S_{\text {int }}$ (see Eq.(3)). The sets of variables, which can be observed from the output, represent the output subsystem $\mathrm{S}_{\mathrm{o}}$ as expressed in Eq.(2). By introducing the Partition Law of Information Rates, the hierarchical decomposition, and the Law of Constraint Loss, including the information blockage analysis, the tools for quantitative estimates of operations and control of a work systems are at the disposal (Conant, 1975).

Further explanation reveals briefly the most important estimates to be used in the information analysis of a work system.

\subsection{Entropy and transmission}

The fundamental parameter related to the variable $\mathrm{X}$ or $\mathrm{Y}$ of a system is the entropy expressed by Shannon (1949) as

$H(x)=-\Sigma p(x) \log 2 p(x)$

The system entropy considers a system of variables and yields

$H(s)=-\sum p(s) \log 2 p(s)$ 
The transmission defines the degree of dependency of not statistically independent variables $X_{1}$ and $X_{2}$

$$
\begin{aligned}
\mathrm{T}\left(\mathrm{X}_{1}: \mathrm{X}_{2}\right)= & \mathrm{H}\left(\mathrm{X}_{1}\right)+\mathrm{H}\left(\mathrm{X}_{2}\right)-\mathrm{H}\left(\mathrm{X}_{1} \mathrm{X}_{2}\right. \\
& =\mathrm{H}\left(\mathbf{X}_{1}\right)-\mathrm{HX}_{2}\left(\mathbf{X}_{1}\right) \\
& =\mathrm{H}\left(\mathbf{X}_{2}\right)-\mathrm{HX}_{1}\left(\mathbf{X}_{2}\right)
\end{aligned}
$$

With other words, the transmission is a quantitative measure of relatedness between the variables $\mathrm{X}_{1}$ and $\mathrm{X}_{2}$.

For structuring and optimising the system's architecture, as well as the operations of the work system, quantitative estimates of the entropy and the transmission are not very useful. They do not consider the past history constraints related to the present values. This was the reason for introducing the Entropy rates and the Transmission rates into the analysis of dynamic systems (Shannon, Weaver, 1949).

The entropy rate $\overline{\mathrm{H}}(\mathrm{X})$ is expressed as follows

$$
\bar{H}(X)=\lim _{m \rightarrow \infty} \frac{1}{m} H(X(t), X(t+1), \ldots X(t+m-1))
$$

The transmission rate $\bar{T}\left(X_{1}: X_{2}\right)$ is expressed as

$$
\begin{aligned}
\overline{\mathrm{T}}\left(\mathrm{X}_{1}: \mathrm{X}_{2}\right)=\overline{\mathrm{H}}\left(\mathrm{X}_{1}\right)+\overline{\mathrm{H}}\left(\mathrm{X}_{2}\right) & -\overline{\mathrm{H}}\left(\mathrm{X}_{1}, \mathrm{X}_{2}\right) \\
& =\overline{\mathrm{H}}\left(\mathrm{X}_{1}\right)-\overline{\mathrm{H}}_{\mathrm{X} 2}\left(\mathrm{X}_{1}\right) \\
& =\overline{\mathrm{H}}\left(\mathrm{X}_{2}\right)-\overline{\mathrm{H}}_{\mathrm{X} 1}\left(\mathrm{X}_{2}\right)
\end{aligned}
$$

and measures the constraint per step holding between the dynamic variables. The transmission rate is an important survival parameter of a system and a limit to its ability to cope.

The system channel capacity $\mathrm{C}$ is responsible for a successful or unsuccessful transmission of information from the source to the receiver. The system designer should take into account this point very carefully.

An important law governing the information is the Partition Law of Information Rates, which was introduced by Conant (Conant, 1975). The total rate of information a systems transmits from the input to the output is given as

$$
F=F_{1}+F_{b}+F_{c}+F_{n}=\sum_{j=1}^{n} \bar{H}\left(X_{j}\right)
$$


$F_{t}$ is the throughput rate estimating the input - output flow rate relations in a work system. It is responsible for the survival of the system and must be considered in relation to the system's channel capacity $\mathrm{C}_{\mathrm{s}}$.

$F_{t}=\bar{T}\left(E: S_{o}\right)$

E - input information direct from the environment;

$F_{b}$ is the blockage rate defining the part of the input information to be blocked within the system, not allowing to affect the output. The $F_{b}$ is important because it blocks all irrelevant information, which does not contribute to the output formation of the work systems $\mathbf{S}$.

$\mathrm{F}_{\mathrm{b}}=\overline{\mathrm{T}}_{\mathrm{So}}\left(\mathrm{E}: \mathrm{S}_{\mathrm{in}}\right)$

The above expression indicates that the input variables $E\left(X_{1}, X_{2}, \ldots X_{n}\right)$ affect the internal system $S_{\text {int }}$ and should be blocked in terms of the output.

The co-ordination rate $\mathrm{F}_{\mathrm{c}}$ estimates the total co-ordination between all $\mathrm{n}$-variables in the work system S. It is expressed as follows

$F_{c}=\bar{T}\left(X_{1}: X_{2}: \ldots: X_{n}\right)$

It is important to find the co-ordination rate between the subsystems which describes the coupling as weak or strong. For a successful operation a minimum of co-ordination between the subsystems must be realised.

The system $S$ yields an amount of uncertainty per unit (step, time ...) specified as the noise rate $F_{n}$. It corresponds to the internally formed noise information from unknown sources.

The aim of this brief introduction into some tools for quantitative information analysis of a work system is to show the degree of complexity the human operator has to master in order to operate and control a work system possible under the optimal conditions. From this discussion is also evident the type and amount of the theoretical, as well as practical knowledge a Subject has to exhibit in order to operate a work system.

That is to say that the Subject must be able to understand and to use the laws governing the operations and control, in order to accomplish the objectives. On the other hand the information laws are of limited validity. The work systems are not stationary, the condition of ergodicity is not fulfilled, and the experimental data for estimating higher order of multivariate probabilities are insufficient. The estimates of entropy rates and transmission rates (Eq. 7-13) may for these reasons be only very carefully applied.

In this situation, the question is how to solve these problems in an industrial environment. 


\section{SUBJECT ORIENTED KNOWLEDGE PROCESSING AND CONTROL}

\subsection{The competence of the subject}

The analysis of the work system clearly indicates that the Subject is the focal point in operating and controlling the manufacturing activities. For this task he has to posses several abilities, enabling him to do these jobs with competence, reliability and with the sense of responsibility.

The most important characteristics of the Subject is his competence about a variety of tasks related to the organisational structure of WS, the operations involved in the manufacture of a specified output, and the art of control of the WS in order to accomplish a set of objectives $\{Z\}$.

Further abilities of the Subject on the job level can be listed as follows: the ability to trust, to communicate, to work in a team, to shear the knowledge, to adapt quickly to unpredictable situations, to be responsible. And this list is, of course, not exhausted.

The competence of a Subject depends to a great deal on his knowledge and experience. His further abilities are closely related to his character, but can also be, to some extent, influenced by the education, training and practical work within the industrial environment.

A formal description of the Subject competence for the purpose of modelling the future manufacturing systems is perhaps, at present, not possible. The same applies also to the formal expressions for the above mentioned abilities of the Subject. Of course, in the literature there are attempts described how to formalise the Subject's characterisation (Morray, 1990). The results are, however incomplete and of limited value. Therefore, the search for an acceptable generalised solution with distinct practical approach to solve the problem is imminent.

\subsection{The role of education and training in forming a competent subject}

The competence of a Subject results from his knowledge and experience. Therefore, we should focus our attention to a type of education \& training, which will give to an individual the chance of getting relevant and broad engineering knowledge, to develop the ability to work in a team, to understand the benefits of self-organisation, to provide an opportunity to become creative, to honour the time and the deadlines. Through the practical training and work, the Subject may gain the experience, as an important ingredient enabling him to become a competent and autonomous person within the terms of reference.

The role of education and training in manufacturing for the 21st century was clearly realised by the SME, which organised in 1996 a world conference on this important field of human endeavour. Many contributions indicate the approaches in various environs dealing with these problems. 
An educational and training model based on the project approach was proposed by Peklenik (Peklenik, 1996) and is briefly discussed in the context of future developments of manufacturing technology.

\subsection{A project approach to develop a competent subject}

The objective of the project approach is to educate and train a Subject (operator, designer, team leader manager, etc.) to became a decision maker with skills, competent, autonomous, co-operative and communicative to other work systems. These abilities of the Subject may provide a work system with significantly greater flexibility and adaptability, making it also possible to implement rational selforganisational steps towards the optimal work structures, operations and control.

A team of students or trainees represents the object to be trained in certain field of there future activities. The supervisor and experienced instructors set up a project, which the team has to implement during the training. The type of project depends upon the objectives which the group is aiming to achieve and is specified by a set of project specifications $\{X\}$, Figure 9. A set of objectives $\left\{Z^{*}\right\}$ defines the goals to be accomplished with this exercise. These are: realisation of a product or technology in order to: trigger the creativity, original thinking and, the systems approach; to understand the product development process as a whole, to overlook the entire manufacturing cycle, to learn how to plan and control the activities in manufacturing etc. Particular attention is paid to develop the abilities working in a team and to solve problems in a given time.

The content of instructions must be of course, adapted to various levels of responsibility, accordingly. However the major points, as listed in the objectives, are vital for the development of competence of a Subject by applying a very systematic and highly motivated approach.

By educating and training the Subjects with the aim to increase their competence we may be able to realise new concepts in structuring, operating and control the factory systems in the future.

Of course, it will be necessary to develop innovative study and training programs for various levels of jobs. This task may significantly change the methods of education and training in engineering in the future. 


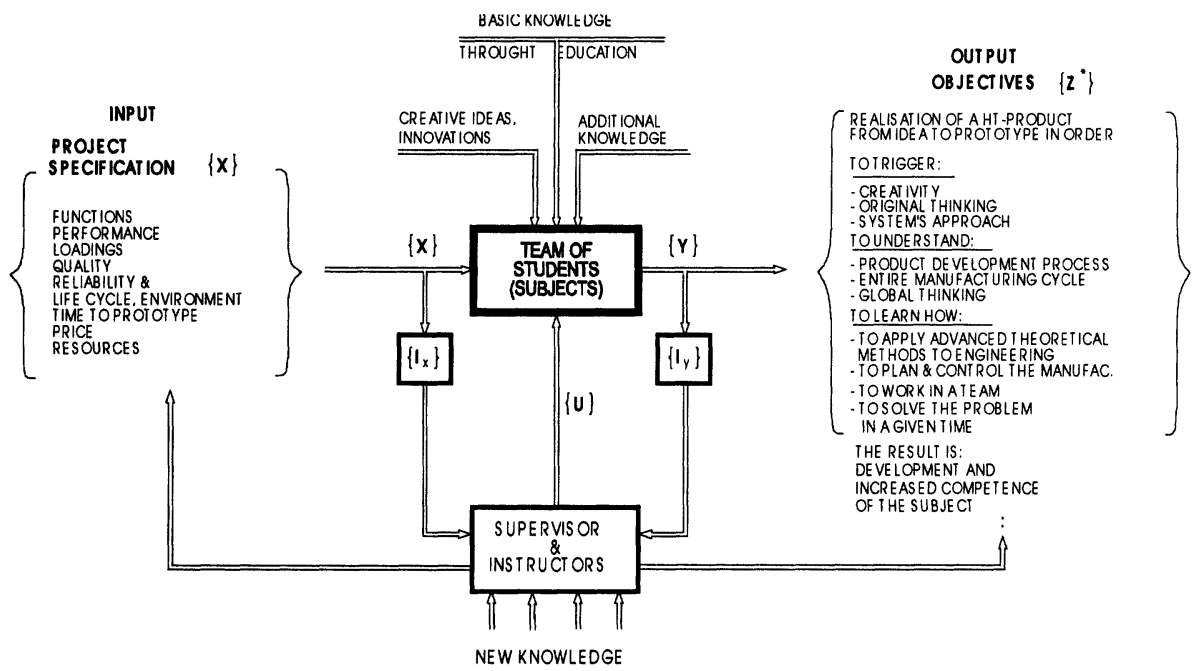

Figure 9: Project approach to develop \& increase the competence of the subjects.

\section{CONCLUSIONS}

The manufacturing system as a factory structure consists of a number of interdependent elementary work systems, integrated by the communications channels for information transfer and the material logistics for transportation of materials, entities.

The elementary work system is analysed from the cybernetic as well as the information viewpoints. Various NS represent the building units for the factory structure. The complexity of the manufacturing systems is illustrated on a microlevel - the grinding process and on a macro-level - a flexible manufacturing system FMS. It is shown that the operation and control of work processes and systems require decisions, which a Subject has to make on an on-line basis. Due to the fact that the behaviours of the system elements generate information of complex nature, the Subject controlling the work system must reveal sufficient competence to make the right and best decisions.

Due to the fact that the work system to be controlled can not be formally described their behaviours are of stochastic nature and are non-linear and is difficult to control, the Subject making the decisions must be a competent and knowledge able one. The quality of the decisions is in direct correlation with his competence. Through proper education and training, the Subject can obtain the necessary knowledge for mastering the problems on levels of his activities. 
Wiendahl P., (1994): "Management and Control of Complexity in Manufacturing", Annals of the CIRP, Vol. 43/2, 533.

Ueda K., (1990): "An Approach to Bionic Manufacturing Systems toward Future Factory", Proc. of the 3rd JSPS-VCC Seminar on Integrated Engineering, Kuala Lumpur, 485.

Ueda K., (1992): "An Approach to Bionic Manufacturing Systems Based on DNAtype Information", Proc. of Inter. Conf. on Object-Oriented Manufacturing Systems, Calgary, 303.

Ueda K., (1992): "A Concept for Bionic Manufacturing Systems Based on DNAtype Information, Proc. of 8th Inter. PROLOMAT Conference, Man in CIM, Tokyo, 853.

Ueda K., (1993): "A Genetic Approach toward Future Manufacturing Systems", in Flexible Manufacturing Systems: Past-Present-Future, edited by J. Peklenik, CIRP, 211.

Ueda K., (1993): "Biological-oriented Paradigm for Artifacts", Proc. of the 1 st Inter. Symposium on Research into Artifacts, University of Tokyo.

Okino N., (1990): "Bionic Manufacturing Systems", Jour. of JSPE, Vol. 56/1, 76.

Okino N., (1993): "Bionic Manufacturing Systems" in Flexible Manufacturing Systems: PastPresent-Future, edited by J. Peklenik, CIRP, 73.

Peklenik J., (1996): FMS - A Complex Object of Control, Keynote paper, Proc. of 6th Inter. PROLOMAT Conference, Man in CIM, Tokyo.

Warnecke H.J., (1993): "The Fractal Company", Springer-Verlag, Berlin.

Ueda K., (1994): "Biological-oriented Paradigm for Artifactual Systems", Proc. of Japan-USA Symposium on Flexible Automation, Kobe, 1263.

Peklenik J., (1994): The Statistical Mechanisms of Chip Formation in Grinding Process, Proc. of the Int. Conf. on Production Eng., Tokyo, Part II, pp. 51-57.

Peklenik J., (1975): Manufacturing Cybernetics, Its Influence on Technological and Technological Developments and the Productivity, Proc. of the 10. Symposium on Production Engineering, Beograd, pp.1-53.

Peklenik J., (1988): Fertigungskybernetik, Eine neue wissenschaftliche Disziplin für die Produktionstechnik, Festvortrag anläßlich der Verleihung des GeorgSchlesinger Preises 1988 des Landes Berlin, TU-Berlin.

Eversheim W., (1994): Verringerung und Beherrschung der Komplexität starkt die Wettbewerbsfahigkeit, Münchener Kolloduium, München, Germany.

Kimura F., (1993): Intelligent Manufacturing Systems - Concepts and Realization, 3. Intern. IMS Symposium, Nov., 30/31, Vienna, Austria.

Wiendahl P., Pritschow G., Milberg J., (1993): Produktions-regelunginterdisziplinare Zusammenarbeit führt zu neuen Ansätzen. Zeischrift für wirtschaftliche Fertigung und Automatisierung ZwF 88 (1993)6, Carl Hanser Verlag, München, Germany. 
Chryssolouris G., (1994): Measuring Complexity in Manufacturing Systems, Working paper.

Peklenik J., (1995): Complexity in Manufacturing Systems, Manufacturing Systems, Vol. 24 , No.1.

Morray N., Lee J., (1990): Trust and Allocation of Function in the Control of Automatic Systems, EPRL-90-05.

Morray N., (1990): A Lattice Theory Approach to the Structure of Mental Models, Phil. Trans. R. Soc. Lond. B 327, 577-583.

SME, (1996) Manufacturing Education for the 21st Century, Proceedings of the Conference, Vol. III, Preparing World Class Manufacturing Professionals, San Diego, March 1996

\section{BIOGRAPHY}

Janez Peklenik Professor of Control and Manufacturing Systems, University of Ljubljana, Slovenia, PhD and Dsc Technical University Aachen (1957, 1961) Professor of Manufacturing Systems, University of Birmingham UK (I964), Professor and Head Dept. Of Control \& Manufacturing Systems, Univ. Ljubljana (1972), Dean 1973/76, Rector of UL 1987/90, Fellow o: CIRP (1966), President (1979/80), Academy of Science \& Arts Slovenia 1972, SME (1986), Academia Europaea 1989, Internat Academy of Eng. Moscow (1995), Awards F.W. Taylor Medal of CIRP 1959 \& SME 1980, Georg Schlesinger Award of Berlin, 1988, Honorary Member of CIRP, 1997, University of Aeronautics/Astronautics Nanjing China, 1982. Published over 300 papers in prof. Journals, Editor and Chief CIRPJournal on Manufacturing Systems (1968). 